\title{
Photoionic devices with receptor-functionalized fluorophores
}

\author{
A. Prasanna de Silva, H. Q. Nimal Gunaratne, Thorfinnur Gunnlaugsson, Colin P. \\ McCoy, Pamela R. S. Maxwell, Jude T. Rademacher and Terence E. Rice
}

School of Chemistry, Queen's University, Belfast BT9 5AG, Northern Ireland

\begin{abstract}
Fluorophores can be connected to ion receptors so as to permit extensive overlap, be geometrically orthogonal or be separated by a spacer. Each of these three formats 1-3 has led to applications as ion sensors or switches. We focus on 'fluorophore-spacer-receptor' systems whose modular structure allows semiquantitative design according to the principle of photoinduced electron transfer (PET). The fluorescence of these systems can be switched 'on' or 'off' when confronted with ions. Several new examples 15-17 responding to $\mathrm{Na}^{+}, \mathrm{H}_{3} \mathrm{~N}^{+} \mathrm{CH}_{2} \mathrm{CH}_{2} \mathrm{CH}_{2} \mathrm{CO}_{2}^{-}$ and $\mathrm{H}^{+}$are described. 17 and 18 are cases where kinetic factors become important in addition to the usual thermodynamic design criteria. Expansion of the basic threemodule system by the addition of a separate receptor with a different ion binding profile as in 19 gives rise to molecular AND logic gates. On the other hand, OR logic gates such as 20 can be obtained from the basic system provided that the receptor is deliberately chosen to be nonselective under the conditions of use.
\end{abstract}

\section{INTRODUCTION}

Molecular photoionic devices can be defined as chemical species which combine photonic and ionic interactions for useful purposes. Perhaps the most important of these are found in the rhodopsin systems within the eye. An incoming photon signal is eventually transduced into a flux of $\mathrm{Na}^{+}$and $\mathrm{K}^{+}$ions within the optic nerve reaching all of the way to the brain which registers the visual response (1). The fact that vision is our busiest information input channel adds to the value of this particular photoionic device. Of no less importance, at least to its bacterial owners, is the bacteriorhodopsin assembly which supplies the necessary energy as a photogenerated $\mathrm{H}^{+}$gradient (2). There are far simpler synthetic systems, however, which perform functions which are sought by various groups of users. Our concern in this article is with devices which have ionic inputs and fluorescence output. Such ionically-responsive fluorescent molecules find their widest use as sensors (3) and switches. On one hand, ions of many types perform vital biological functions and need to be monitored in many situations of sickness and health. On the other hand, fluorescence photons are a natural bridge between our eyes and the molecular world we need to observe.

\section{CONNECTING FLUOROPHORES AND ION RECEPTORS}

Fluorophores can be connected to ion receptors in at least three distinct formats 1-3 (4). The integrated

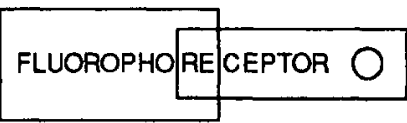

1

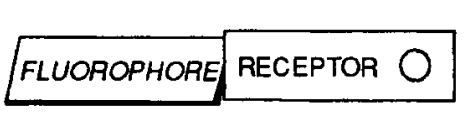

2

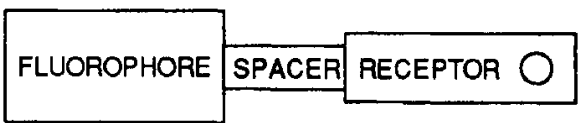

3

system 1 has extensive overlap between the $\pi$ electron systems of the fluorophore and the ion receptor. Ion binding naturally leads to perturbation of the energy of the fluorophore excited state, especially if it has internal charge transfer (ICT) character (5) due to the presence of electron donor and acceptor terminals. 
So ion-induced spectral shifts are to be expected. This is most clearly seen in the fluorescence excitation spectra. Emission spectral shifts are rarer, because of the movement of the ion out of the receptor during the lifetime of the emitting state (6). Such cation movement is caused by the electrostatic repulsion from the positive pole of the ICT excited state close by. The excitation (or emission) spectral shifts can be exploited for the fluorescence monitoring of intracellular ion concentrations. Roger Tsien (presently at San Diego) pioneered this chemical service to the biological research community (7). Sensor 4 is one of the most popular cases for the measurement and imaging of $\mathrm{Ca}^{2+}$ with micrometer and millisecond resolution.

The twisted system 2 possesses two orthogonal $\pi$ electron systems corresponding to the receptor and the fluorophore which is usually caused by steric influences. For example, Haruo Shizuka at Gunma described the molecule 5 (8) where the peri hydrogens of the anthracene force the 9-(4'-dimethylaminophenyl) group to take up a plane perpendicular to that of the anthracene. 5 is weakly fluorescent with an additional longwavelength component, but protonation causes strong recovery of the anthracene-like emission. We find it convenient to analyse twisted systems such as Tsien's 6 (9) according to the principle of photoinduced electron transfer (PET) (10) to be described shortly. In general however, the theory of twisted intramolecular charge transfer (TICT) excited states must be applied to the twisted system 2 (11).

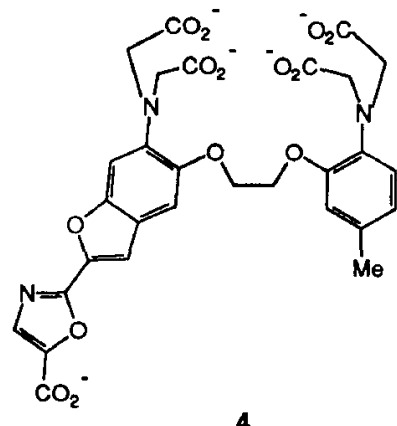

4

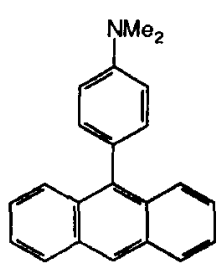

5

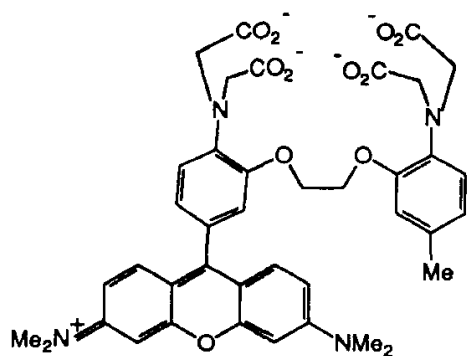

6

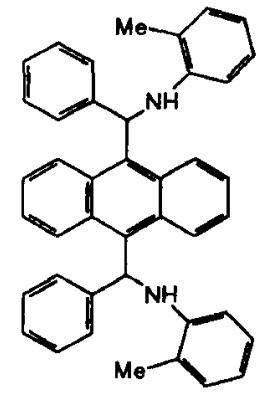

7

The third approach to connecting an ion receptor with a fluorophore is according to the spaced format 3. Such 'fluorophore-spacer-receptor' systems are special because the spacer isolates the terminal functionalities in most respects except for a few relatively long range interactions. These cases can be considered quite legitimately to be supramolecular systems since their components can be readily recognised $(12,13)$. This leads to a simple molecular heredity where the ion binding properties and spectroscopic parameters (in both absorption and emission) of the assembled sensor is nearly quantitatively inherited from its parent fluorophore and receptor (14). The crucial exception is the fluorescence quantum yield of the sensor which is much lower than that of the parent fluorophore in well-designed cases. A long range (15) PET (16) from the ion-free receptor to the fluorophore which overpowers fluorescence is at the heart of this design. Upon encountering the chosen ion at a high enough concentration however, the receptor module becomes ion-bound and its oxidation potential increases sharply. Then the thermodynamics for PET become unfavourable. Such suppression of PET allows the fluorescence to become the dominant path for excited state decay. This leads to the 'switching on' of fluorescence upon ion admission to the sensor/switch $(4,17)$. Of course, the situation is reversible and ion removal allows the fluorescence to subside to its 'switched off' state. Such 'off-on' switching for fluorescence under ionic control is truly dramatic with fluorescence enhancement factors of two or three orders of magnitude not being uncommon $(10,18)$. The modular concept of the spaced system 3 along with its straightforward theoretical basis allows us to design sensors or switches to suit different ions over various concentration ranges and selectivity profiles. Similarly, different requirements of absorption colour, emission colour and even luminescence type (fluorescence or phosphorescence) can be satisfied. Another consequence of modular systems is their easy expansion. Additional modules with chosen functions can be appended to the basic 'fluorophore-spacer-receptor' system in order to carry ionically switchable fluorescence into new areas of research.

Fluorescent PET sensors and switches based on the spaced system 3 had grown out of an international research effort. 7 appears to be the earliest case where Tadao Nakaya et al at Osaka noted its weak fluorescence (19). Its heart is the 9-aminomethylanthracene structure which has seen several reincarnations in sensors for various species (18a, c, 20). Following Albert Weller's seminal studies on PET at Stuttgart (21), the first fluorescent PET sensors 8 and 9 emerged. These arose from Herbert Morawetz's and Ben 
Selinger's laboratories in Brooklyn (22) and Canberra (23) respectively. In these instances, the receptor character of the amine group was recognised and $\mathrm{H}^{+}$-induced fluorescence enhancement was observed. We have summarized the contributions of these and other pioneers in a recent review (17).

\section{RECENT EXAMPLES OF 'FLUOROPHORE-SPACER-RECEPTOR' SYSTEMS}

The aminomethylaromatic motif continues to appear in successful fluorescent PET sensor designs for $\mathrm{H}^{+}$. Polyazamacrocycle $\mathbf{1 0}$ is such a case (24). The presence of multiple protonation sites can have several

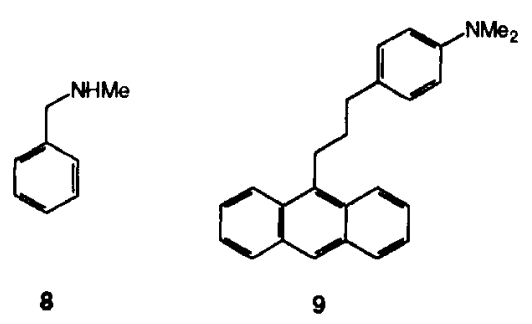
effects $(18 \mathrm{a}, \mathrm{c})$. Multiple protonation requires rather high proton concentrations. Also the possibility of PET is entirely removed only when all the lone electron pairs of the amine units have been disabled. Therefore the $\mathrm{pH}$ dependence of the fluorescence intensity shows multiple sigmoidal steps and strong fluorescence enhancements are seen only at rather high degrees of protonation. As expected for fluorescent PET systems (17), 10 shows essentially the same $\mathrm{pK}_{\mathrm{a}}$ values whether determined by fluorimetry, absorptiometry or potentiometry.

Amines are not the only receptors to be designed into fluorescent PET pH sensors. Incidentally, carboxylate receptors made an appearance in this context in 1989 (14). Phenolate and pyridine units have been represented by 11 and 12 respectively. It has been appreciated for some time that the luminescence of tris $\left(2,2^{\prime}\right.$-bipyridine)Ru(II) can be quenched by phenolates via PET (25). The corresponding phenols would be rather less effective quenchers via electron donation. So it was natural that an intramolecular version would produce an effective luminescent $\mathrm{pH}$ sensor. In 11, the phenolate/phenol unit has been elaborated into a calix[4]arene (26). While 11 showed a $\mathrm{H}^{+}$-induced fluorescence enhancement (FE) of 6, a derivative with two lumophore units could only manage a FE value of 1.8 in spite of the statistical advantage (10). This effect could be attributed to a steric inhibition of the solvent reorganization vital to rapid PET. The sensor 12 could be designed confidently from available data because the calculated thermodynamics for PET was favorable for protonated 12 while the opposite was true of unprotonated 12 . Thus, fluorescence

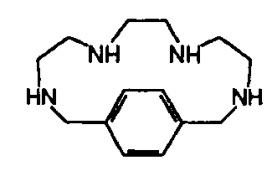

10

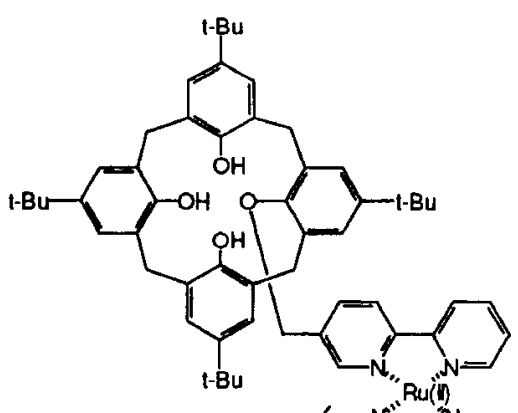

11

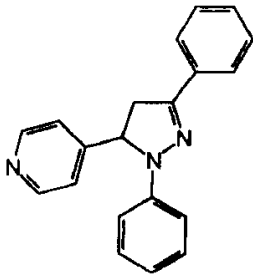

12

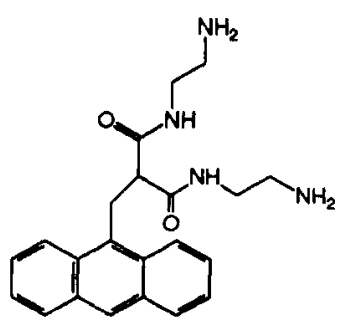

13

was expected to 'switch off' upon protonation (27). 12 was known in the literature as a fluorescent compound, but not as a sensor (28). A remarkable feature of the sensor family represented by 12 is that the emission spectra of individual members cover most of the visible region while they all show uniformly strong switching behaviour.

Sensors of the 'fluorophore-spacer-receptor' type 3 for d-block metal ions usually show ion-induced fluorescence quenching which can arise by PET and/or electronic energy transfer (29). The latter is feasible since many $d-d$ metal centered excited states can lie at lower energies than the $\pi \pi^{*}$ states of commonly used fluorophore units. In the case of 13 , the growth of a d-d absorption band characteristic of a $\mathrm{Cu}$ (II) complex clearly correlates with the fluorescence quenching as the $\mathrm{pH}$ is increased to encourage complexation (30).

Tsien's fluorescent sensor 14 for $\mathrm{Na}^{+}$is based on the integrated system 1 and gives a $\mathrm{Na}^{+}$-induced shift of $12 \mathrm{~nm}$ in the excitation spectrum (31). We have now incorporated his core receptor into a spaced system 3 in order to obtain large enhancements of fluorescence emission in the presence of $\mathrm{Na}^{+}$. Sensor 15 is designed as a PET system and shows good discrimination against $\mathrm{K}^{+}$regarding both binding constants 
(1300 versus 63$)$ and $\mathrm{FE}$ values (12 versus 4.6$)$ in methanol:water $(1: 1, \mathrm{v} / \mathrm{v})$. The latter performance improves upon our previous cryptand-based example (32).

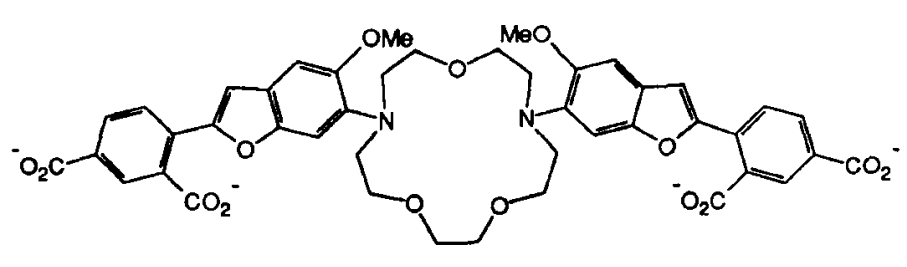

14

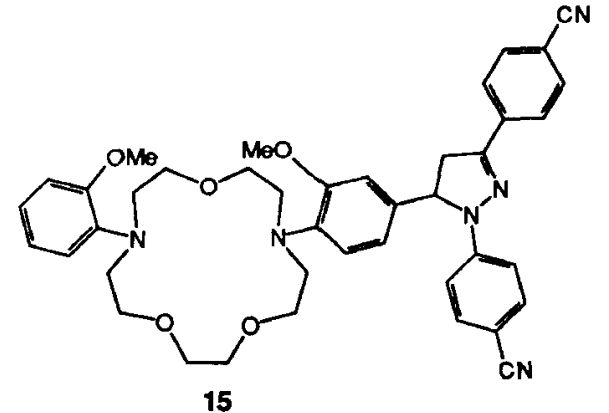

15

After some success with simple inorganic ions, sensor designers must now target more complex organic ions which are equally important in the biological arena. This challenge has been taken up by several laboratories in different ways (33). Our latest effort 16 has been designed to sense the brain neurotransmitter $\mathrm{GABA}\left(\mathrm{H}_{3} \mathrm{~N}^{+} \mathrm{CH}_{2} \mathrm{CH}_{2} \mathrm{CH}_{2} \mathrm{CO}_{2}^{-}\right)$. The PET-active azacrown ether unit binds the ammonium terminal of GABA whereas the guanidinium group holds the carboxylate end. The anthracene moiety serves a dual role as fluorophore and as the rigid backbone which confers linear recognition capability on 16. In practice, 16 shows a FE value of 2.4 and a binding constant of 36 with GABA in methanol:water $(3: 2, \mathrm{v} / \mathrm{v}, \mathrm{pH} 9.5)$. Importantly, the fluorescence of 16 does not respond significantly to the presence of glutamic acid or glycine.

The substantial literature on fluorescent PET sensors and switches can be largely understood on the basis of the thermodynamic criteria outlined in the previous section for the spaced system 3 (17). We now find

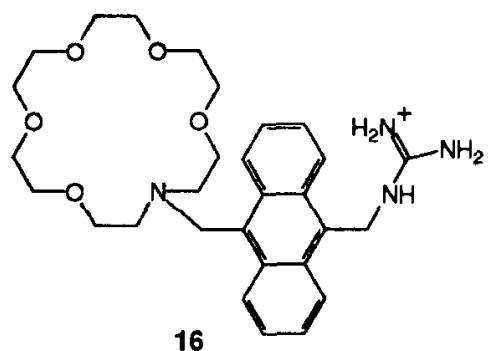

16

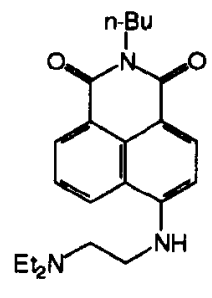

17

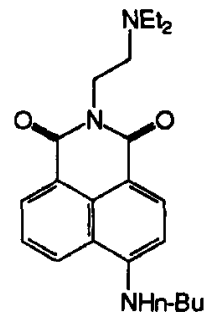

18 that regioisomers 17 and 18 are remarkable because kinetic factors are necessary to rationalize their $\mathrm{H}^{+}$-responsive fluorescence behavior. When $\mathrm{H}^{+}$free, there is no thermodynamic obstacle to PET in either case. Nevertheless, 17 shows a large FE value of 25 upon protonation whereas 18 is largely unaffected.

This is because the 4-amino-1,8-naphthalimide fluorophore develops a strong dipole moment of 11D upon excitation which, depending on its orientation with respect to the transiting electron, can electrically help or hinder PET. This photogenerated molecular-scale electric field controls the kinetics of the electron transfer and the PET sensory capability of the device. Such 'one way' control of electron traffic may be relevant to understanding how the photosynthetic reaction centre operates (34).

\section{FLUORESCENT PET SYSTEMS AS LOGIC GATES}

The previous sections have outlined how ionically-switchable fluorescent systems can be designed. Switchable fluorescence can serve as an easily comprehensible output signal from a molecular device. The exciting light would act as a power supply and various ions can provide input signals. Switches which supply an output only when certain input conditions are satisfied would then behave as gates with various logic functions. Molecular logic gates have excited the imagination of the public because of their potential in molecular computation. 19 is a molecular AND gate which outputs a high level of fluorescence only when $\mathrm{H}^{+}$and $\mathrm{Na}^{+}$inputs are supplied. From a sensor perspective, 19 responds to the simultaneous presence of $\mathrm{H}^{+}$and $\mathrm{Na}^{+}$i.e. it is a coincidence detector. 19 succeeds because its amine and benzocrown ether units are both PET-active and the PET processes are blocked when these receptors selectively bind $\mathrm{H}^{+}$and $\mathrm{Na}^{+}$ respectively. The device 19 marshals two types of ions and two kinds of photons without any external connections - a remarkable piece of molecular self-organization (35).

Selective binding of each input ion by the correct receptor module was crucial to the successful operation of 19 as an AND gate. In contrast, OR gates such as 20 depend on the receptor unit to be practically 

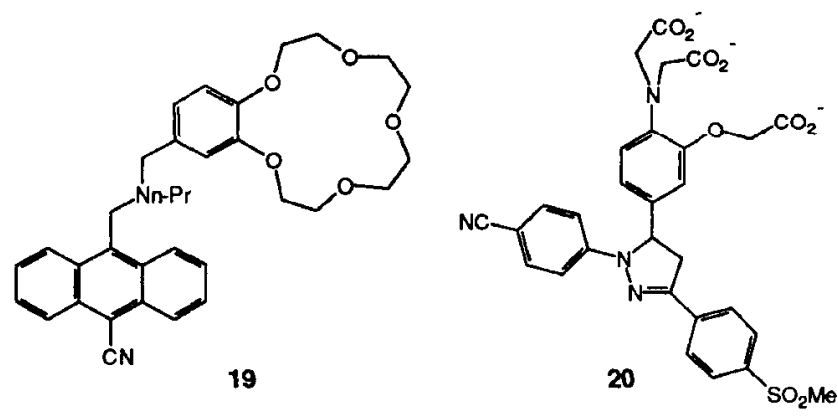

nonselective towards the two input ions as far as the fluorescence output level is concerned. In this case the ion-induced $\mathrm{FE}$ values are 67 and 57 for $\mathrm{Ca}^{2+}$ and $\mathrm{Mg}^{2+}$ respectively. Both cations cause similar conformational changes in the receptor unit and subsequently, similar increases in its oxidation potential. Thus, PET is suppressed to similar extents (36). From a sensor perspective, the binding constants of 20 with $\mathrm{Ca}^{2+}$ and $\mathrm{Mg}^{2+}$ are such that the latter is detected with near-complete rejection of the former under simulated physiological conditions.

\section{CONCLUSION}

This article is an attempt to show how useful photoionic devices can arise from the arranged marriage of ion receptors and fluorophores. The cooperativity between supramolecular/co-ordination chemists and photophysicists can be a very positive one. Molecular information gathering with sensors and molecular information processing with gates or switches are two fields (37) which stand to benefit from research into photoionic devices.

\section{ACKNOWLEDGEMENTS}

We are grateful to the following institutions and programs: Queen's University, University of Colombo, EPSRC, DENI, IAESTE, ERASMUS, Nuffield Foundation and NATO (no. 921408 for collaboration with Jean-Philippe Soumillion at Universite Catholique de Louvain). Without their support, our own research would have been the poorer.

\section{REFERENCES}

1. Principles of Neural Science, 3rd ed., (E. R. Kandel, J. H. Schwartz and T. M. Jessell, eds.), Elsevier, New York, 1991.

2. M. A. El-Sayed, J. Griffiths, L. Song and N. Zhang, Pure Appl. Chem. 67, 149 (1995).

3. A. Fernandez-Gutierrez and A. Munoz de la Pena, in Molecular Luminescence Spectroscopy: Methods and Applications. Part I, (S. G. Schulman, ed.), Wiley, New York, 1985, p 371; Fluorescent Chemosensors for Ion and Molecule Recognition, (A. W. Czarnik, ed.), ACS Symp. Ser. 538 (1992); B. Valeur, in Probe Design and Chemical Sensing. Topics in Fluorescence Spectroscopy. Vol 4, (J. R. Lackowicz, ed.), 1994, p 21; B. Valeur and E. Bardez, Chem. Brit. 31, 216 (1995).

4. R. A. Bissell, A. P. de Silva, H. Q. N. Gunaratne, P. L. M. Lynch, G. E. M. Maguire and K. R. A. S. Sandanayake, Chem. Soc. Rev. 21, 187 (1992).

5. H. Shizuka, Acc. Chem. Res. 18, 141 (1985).

6. M. M. Martin, P. Plaza, N. D. Hung, Y. H. Meyer, J. Bourson and B. Valeur, Chem. Phys. Lett. 202, 425 (1993); J. F. Letard, R. Lapouyade and W. Rettig, Pure Appl. Chem. 65, 1705 (1993).

7. R. Y. Tsien, Am. J. Physiol. 263, C723 (1992); R. Y. Tsien, Chem. Eng. News 34 (July 18, 1994).

8. H. Shizuka, T. Ogiwara and E. Kimura, J. Phys. Chem. 89, 4302 (1985).

9. A. Minta, J. P. Y. Kao and R. Y. Tsien, J. Biol. Chem. 264, 8171 (1989).

10. A. P. de Silva, H. Q. N. Gunaratne, A. T. M. Kane and G. E. M. Maguire, Chem. Lett. 125 (1995).

11. W. Rettig, Angew. Chem. Int. Ed. Engl. 25, 971 (1986); W. Rettig, Top. Curr. Chem. 169, 253 (1994).

12. V. Balzani and F. Scandola, Supramolecular Photochemistry, Ellis-Horwood, Chichester, 1991.

13. J.-M. Lehn, Angew. Chem. Int. Ed. Engl. 27, 89 (1988); 29, 1304 (1990).

14. A. P. de Silva, S. A. de Silva, A. S. Dissanayake and K. R. A. S. Sandanayake, J. Chem. Soc. Chem. Commun. 1054 (1989).

15. G. L. Closs and J. R. Miller, Science 240, 440 (1988); J. W. Verhoewen, Pure Appl. Chem. 62 , 1585 (1990); M. N. Paddon-Row, Acc. Chem. Res. 27, 18 (1994). 
16. Photoinduced Electron Transfer. Parts A-D, (M. A. Fox and M. Chanon, eds.) Elsevier, Amsterdam, 1988; Photoinduced Electron Transfer I-V, (J. Mattay, ed.), Top. Curr. Chem. 156, (1990); 158, (1991); 159, (1992); 163, (1992); 168, (1993); M. R. Wasielewski, Chem. Rev. 92, 435 (1992); G. J. Kavarnos, Fundamentals of Photoinduced Electron Transfer, VCH, New York, 1993.

17. R. A. Bissell, A. P. de Silva, H. Q. N. Gunaratne, P. L. M. Lynch, G. E. M. Maguire, C. P. McCoy and K. R. A. S. Sandanayake, Top. Curr. Chem. 168, 223 (1993).

18. a) M. E. Huston, K. W. Haider and A. W. Czarnik, J. Am. Chem. Soc. 110, 4460 (1988); b) A. P. de Silva, and H. Q. N. Gunaratne, J. Chem. Soc. Chem. Commun. $186(1990)$; c) R. A. Bissell, E. Calle, A. P. de Silva, S. A. de Silva, H. Q. N. Gunaratne, J. L. Habib-Jiwan, S. L. A. Peiris, R. A. D. D. Rupasinghe, T. K. S. D. Samasasinghe, K. R. A. S. Sandanayake and J.-P. Soumillion, $J$. Chem. Soc. Perkin Trans. 21559 (1992).

19. T. Nakaya, T. Tomomoto and M. Imoto, Bull. Chem. Soc. Jpn. 39, 1551 (1966).

20. J. P. Konopelski, F. Kotzyba-Hibert, J.-M. Lehn, J.-P. Desvergne, F. Fages, A. Castellan and H. Bouas-Laurent, J. Chem. Soc. Chem. Commun. 433 (1985); F. Fages, J.-P. Desvergne, H. BouasLaurent, P. Marsau, J.-M. Lehn, F. Kotzyba-Hibert, A.-M. Albrecht-Gary and M. Al-Joubbeh, J. Am. Chem. Soc. 111, 8672 (1989); A. P. de Silva and R. A. D. D. Rupasinghe, J. Chem. Soc. Chem. Commun. 1669 (1985); A. P. de Silva, and S. A. de Silva, J. Chem. Soc. Chem. Commun. 1709 (1986); E. U. Akkaya, M. E. Huston and A. W. Czarnik, J. Am. Chem. Soc. 112, 3590 (1990); M. E. Huston, E. U. Akkaya and A. W. Czarnik, J. Am. Chem. Soc. 111, 8735 (1989); A. W. Czarnik, Acc. Chem. Res. 27, 302 (1994).

21. A. Weller, Pure Appl. Chem. 16, 115 (1968).

22. Y. C. Wang and H. Morawetz, J. Am. Chem. Soc. 98, 3611 (1976).

23. B. K. Selinger, Aust. J. Chem. 30, 2087 (1977).

24. M. A. Bernado, A. J. Parola, F. Pinas, E. Garcia-Espana, V. Marcelino, S. V. Luis and J. F. Miravet, J. Chem. Soc. Dalton Trans. 993 (1995).

25. K. Miedlar and P. K. Das, J. Am. Chem. Soc. 104, 7462 (1982); C. Rajagopal, C. A. Gnanaraj, A. Mathew and C. Srinivasan, J. Photochem. Photobiol. A: Chem. 69, 83 (1992); D. M. Vera, G. A. Arguello, G. A. Arguello and H. E. Gsponer, J. Photochem. Photobiol. A: Chem 76, 13 (1993).

26. R. Grigg, J. M. Holmes, S. K. Jones and W. D. J. A. Norbert, J. Chem. Soc. Chem. Commun. 185 (1994).

27. A. P. de Silva, H. Q. N. Gunaratne and P. L. M. Lynch, J. Chem. Soc. Perkin Trans.2 685 (1995).

28. L. Szucs, Chem. Zvesti. 23, 671 (1969).

29. E. Kimura, S. Wada, M. Shinoya, T. Takahashi and Y. litaka, J. Chem. Soc. Chem. Commun. 397 (1990); S. C. Rawle and P. Moore, J.Chem. Soc. Chem. Commun. 684 (1992); E. Fujita, S. J. Milder and R. S. Brunswig, Inorg. Chem. 31, 2079 (1992).

30. L. Fabrizzi, M. Licchelli, P. Pallavicini, A. Perotti and D. Sacchi, Angew. Chem. Int. Ed. Engl. 33, 1975 (1994).

31. A. Minta and R. Y. Tsien, J. Biol. Chem. 264, 19449 (1989).

32. A. P. de Silva, H. Q. N. Gunaratne and K. R. A. S. Sandanayake, Tetrahedron Lett. 31, 5193 (1990).

33. F. Fages, J.-P. Desvergne, H. Bouas-Laurent, J.-M. Lehn, J. P. Konopelski, P. Marsau and Y. Barrans, J. Chem. Soc. Chem. Commun. 655 (1990); A. P. de Silva and K. R. A. S. Sandanayake, Angew. Chem. Int. Ed. Engl. 29, 1173 (1990); S. R. Adams, A. T. Harootunian, Y. J. Buechler, S. S. Taylor and R. Y. Tsien, Nature 349, 694 (1991); F. Fages, J.-P. Desvergne, K. Kampke, H. Bouas-Laurent, J.-M. Lehn, M. Meyer and A.-M. Albrecht-Gary, J. Am. Chem. Soc. 115, 3658 (1993); M. Inouye, K. Hashimoto and K. Isagawa, J. Am. Chem. Soc. 116, 5517 (1994).

34. The Photosynthetic Reaction Center. Vols. I and II, (J. Diesenhofer and J. R. Norris, eds.), Academic Press, San Diego, 1993.

35. A. P. de Silva, H. Q. N. Gunaratne and C. P. McCoy, Nature 364, 42 (1993).

36. A. P. de Silva, H. Q. N. Gunaratne and G. E. M. Maguire, J. Chem. Soc. Chem. Commun. 1213 (1994).

37. A. P. de Silva and C. P. McCoy, Chem. Ind. 992 (1994). 